\title{
Physical Principles of Non-contact Ultrasonic Frequency Sensors Creation for the Study of Nanocrystalline Ferromagnetic Materials
}

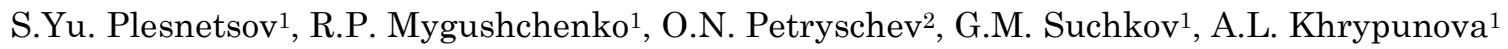 \\ ${ }_{1}$ National Technical University "Kharkiv Polytechnic Institute", 2, Kyrpychev Str., 61002 Kharkiv, Ukraine \\ 2 National Technical University of Ukraine "Kiev Polytechnic Institute named after Igor Sikorsky", \\ 37, Peremohy Ave., 03056 Kiev, Ukraine
}

(Received 31 October 2017; published online 29 April 2018)

\begin{abstract}
A mathematical model is developed to determine the force impacts that are formed when the electromagnetic field is transformed into a field of ultrasonic oscillations in the skin layer of an electrically conductive ferromagnetic material of an anisotropic magnetic permeability. The main factors determining the excited acoustic field with allowance for permissible limitations are established. It is shown that the main contribution to the acoustic vibrations energetics is made by the magnetostrictive component of the skin layer material, in which the high-frequency electromagnetic field is transformed into an acoustic field.
\end{abstract}

Keywords: Mathematical model, Field transformation, Boundary-value problem, Skin layer of metal, Ferromagnet, Electrically conductive material, Elastic vibrations, Electromagnetic field, Force impact.

DOI: 10.21272/jnep.10(2).02004

PACS numbers: $43.35 . Z c, 43.35 . N s, 68.60 . B s$

\section{INTRODUCTION}

Magnetic materials are the basic materials of magnetoacoustics, microwave engineering, magneto-optics and spintronics. Nanostructuring of volumetric materials allows controlling their characteristics in a wide range. Nanocrystalline ferromagnetic soft magnetic materials with low coercive force and ultra-high permeability are most frequently used. The effect of magnetoresistance in film multilayer materials makes it possible to create on their basis high-sensitive heads for magnetic disks, which read information in computers. When developing technology for the formation of both bulk nanostructured materials and film multilayer instrumental structures, it is necessary to control their physical properties by non-destructive testing methods. When developing such methods, an urgent task is to create ultrasonic frequency sensors for the study of nanocrystalline ferromagnetic materials.

In [1], in a general form, the problem of electromagnetic excitation of elastic oscillations in the microthick layers (films) of ferromagnetic metals with the corresponding boundary conditions was formulated and solved, where a linear approximation of the phenomenological theory of magnetostrictive phenomena was used. It is shown that the mathematical model of the transformation process of electromagnetic energy into acoustic one in the skin layer of metal must take into account the coherence of the elastic and magnetic fields in the volume of the dynamically deformed micro-thick layer of an electrically conductive ferromagnet. At the same time wave-length of an excited elastic wave will be significantly larger than skin-layer thickness, therefore providing almost constant within cross-section stress-deformed state of metal layer. Boundaries are determined at which the increase in the mechanical rigidity of the preliminarily magnetized ferromagnet due to the coupling effect of the elastic forces and the forces of the magnetic interaction be-tween the poles of the domains in the deformed thin layer of the ferromagnet can be ignored.
At the same time in order to create the physical basis for thin material surface layer investigation sensor design, by-layer method included, using, for example, frequency change of active electromagnetic field, it is re-quired to define the force parameters affecting skinlayer area of given size, in turn defining most of important attributes of excited acoustic field.

\section{PROBLEM STATEMENT}

Let us consider a model of an electromagnetic transducer (Fig. 1), in which the source of alternating magnetic field (position 1) is formed from $N$ turns of wire, which is laid in concentric circles in a flat coil. The height of the coil is $b$, inner and outer radii of laying turns are $R_{1}$ and $R_{2}$ correspondingly. The coil 1 is placed in vacuum at the distance of $\delta$ over the ferromagnetic metal layer (of $2 h$ thickness) surface 2 . Inside the layer 2 a constant magnetic field is created. Magnetic induction vector is completely defined by its axial component $B_{z}^{0}$, which is a constant in circular area $\rho \leq R_{0}$, where $R_{0}>R_{2}$.

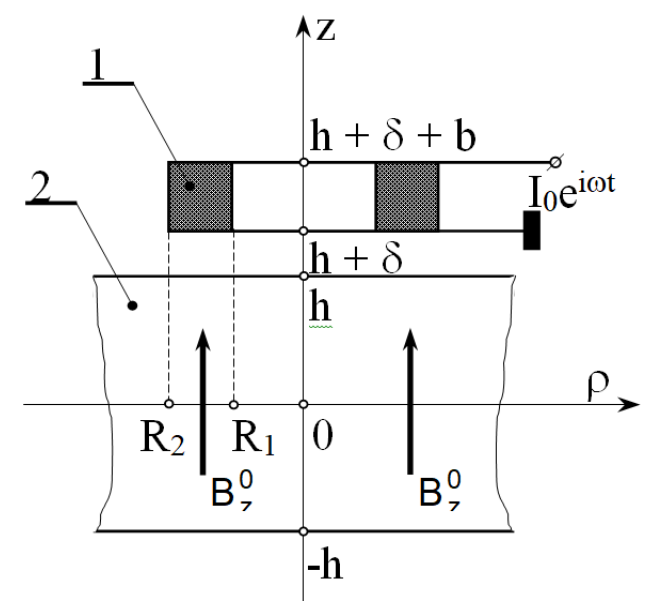

Fig. 1 - Model design scheme (1 - alternating magnetic field; 2 - layer of ferromagnetic metal) 
When alternating electric current $i(t)=I_{0} e^{i \omega t}$ flows through the coil turns, axisymmetric alternating magnetic field appears in the skin layer of the metallic ferromagnetic plate with vector $\vec{H}^{*}(\rho, z, t)$ which intensity varies in time according to the law $e^{i \omega t}$ with the amplitude value $\vec{H}^{*}(\rho, z)$, where $\rho, z$ are the coordinates of the point in the cylindrical coordinate system $(\rho, \varphi, z)$, the plane $z=0$ which is aligned with the middle plane of the layer. The cumulative effect of alternating and constant magnetic fields generates in a volume and on the surface of the ferromagnetic layer the Lorentz forces and magnetostriction forces, which we will henceforth call the Joule forces.

\section{ANALYSIS OF THE FORCE FACTORS THAT ARE FORMED BY THE ELECTROMAGNETIC TRANSDUCER IN THE SKIN LAYER AND IN THE VOLUME OF THE FERROMAGNET}

In order to perform a comparative evaluation of the above-mentioned force factors, we determine the amplitude values of the radial $H_{\rho}^{*}(\rho, z)$ and axial $H_{z}^{*}(\rho, z)$ components of the intensity vector of alternating magnetic field in the ferromagnetic plate. Let us consider alternating magnetic field in the region No.1, where $h \leq z<\infty$. The amplitude value of the intensity vector of alternating magnetic field in this region is denoted by the symbol $\vec{H}^{(1)}(\rho, z)$. In the region No.1 there are external currents with a surface density $\vec{J}^{(1)}=\vec{e}_{\varphi} J_{0}$, where $\vec{e}_{\varphi}-$ a unit vector of the circular axis of the polar angles, and $J_{0}-$ a surface density of the external current, herewith

$$
J_{0}=\frac{I_{0} N}{b\left(R_{2}-R_{1}\right)} f_{1}(\rho) f_{3}(z)
$$

where the regulatory functions $f_{1}(\rho)$ and $f_{3}(z)$ have the following properties:

$$
\begin{gathered}
f_{1}(\rho)=\left\{\begin{array}{l}
1 \forall \rho \in\left[R_{1}, R_{2}\right], \\
0 \forall \rho \notin\left[R_{1}, R_{2}\right],
\end{array}\right. \\
f_{3}(z)=\left\{\begin{array}{l}
1 \forall z \in[h+\delta, h+\delta+b], \\
0 \forall z \notin[h+\delta, h+\delta+b] .
\end{array}\right.
\end{gathered}
$$

Let us introduce the vector potential $\vec{A}(\rho, z)$, where $\operatorname{rot} \vec{A}(\rho, z)=\vec{B}^{(1)}(\rho, z)=\mu_{0} \vec{H}^{(1)}(\rho, z)$. In this case, from the first Maxwell equation $\operatorname{rot} \vec{H}=\vec{J}$ the equation for the vector potential follows, which in extended shape can be written as

$$
-A_{\varphi, z z}(\rho, z)+\frac{1}{\rho^{2}} A_{\varphi}(\rho, z)-\frac{1}{\rho} A_{\varphi, \rho}(\rho, z)-A_{\varphi, \rho \rho}(\rho, z)=\mu_{0} J_{0} f_{1}(\rho) f_{3}(z),
$$

For the vector potential $A_{\varphi}(\rho, z)$ boundary conditions are to be met:

$$
\lim _{r \rightarrow \infty}\left\{\rho A_{\varphi}(\rho, z) ; \rho A_{\varphi, \rho}(\rho, z) ; \rho A_{\varphi, z}(\rho, z)\right\}=0,
$$

where $r=\sqrt{\rho^{2}+z^{2}}$ is the distance to the source.

To solve the equation (2) let us use the direct Hankel transform.

$$
A_{\varphi}(\gamma, z)=\int_{0}^{\infty} \rho A_{\varphi}(\rho, z) J_{1}(\gamma \rho) d \rho,
$$

where $J_{1}(\gamma \rho)$ is Bessel function of the first order - the core of the integral transformation; $\gamma$ is a parameter of the integral transformation (real number, determined on a half-open interval $[0, \infty)$ ). The original image $A_{\varphi}(\rho, z)$ of the unknown function corresponds to the integral image $A_{\varphi}(\gamma, z)$, which is determined from the known value $A_{\varphi}(\gamma, z)$ as a result of the implementation of the inverse integral Hankel transform of the following form

$$
A_{\varphi}(\rho, z)=\int_{0}^{\infty} \gamma A_{\varphi}(\gamma, z) J_{1}(\gamma \rho) d \gamma
$$

Let us influence the (2) equation by the direct transformation (4) receiving

$$
-A_{\varphi, z z}(\gamma, z)+\gamma^{2} A_{\varphi}(\gamma, z)=\mu_{0} R(\gamma, z),
$$

where $R(\gamma, z)=R(\gamma) f_{3}(z) ; R(\gamma)=\frac{I_{0} N}{\gamma b} W(\gamma, R)$;

$$
\begin{gathered}
W(\gamma, R)=\frac{\pi}{2\left(1-R_{1} / R_{2}\right)}\left[\Omega\left(\gamma R_{2}\right)-\frac{R_{1}}{R_{2}} \Omega\left(\gamma R_{1}\right)\right] ; \\
\Omega\left(\gamma R_{j}\right)=J_{1}\left(\gamma R_{j}\right) \mathbf{H}_{0}\left(\gamma R_{j}\right)-J_{0}\left(\gamma R_{j}\right) \mathbf{H}_{1}\left(\gamma R_{j}\right), \\
j=1,2 ; \mathbf{H}_{v}\left(\gamma R_{j}\right)(v=0 ; 1)-\text { Struve function of } v
\end{gathered}
$$
power series.

The solution for the equation (6), which meets the boundary conditions (3), is as follows

$$
A_{\varphi}(\gamma, z)=\left[A_{0}+A(z)\right] e^{\gamma z}+[B+B(z)] e^{-\gamma z},
$$

where

$$
\begin{gathered}
A_{0}=-\mu_{0} I_{0} N W(\gamma, \Gamma) e^{-\gamma h} /\left(2 \gamma^{2}\right) ; \\
W(\gamma, \Gamma)=\frac{\pi e^{-\gamma \delta}}{2\left(1-R_{1} / R_{2}\right)}\left[\Omega\left(\gamma R_{2}\right)-\right. \\
\left.-\frac{R_{1}}{R_{2}} \Omega\left(\gamma R_{1}\right)\right] \frac{\left(1-e^{-\gamma b}\right) .}{\not b} .
\end{gathered}
$$

The way the function $W(\gamma, \Gamma)$ changes defines in fact the lower integration limit when performing the reverse Hankel transform in accordance to (5). Analyzing the $W(\gamma, \Gamma)$ function behavior can show thet in case of $\gamma R_{2} \geq 10$ it has extremely low values for real induc- 
tive coil sizes. Therefore integration by (5) on the interval $\left[\gamma R_{2}, \infty\right)$ has no significant impact on reverse Hankel transform. Thus, instead of infinity as upper integration limit in (5) values $\gamma_{\max } \cong 10 / R_{2}$ can be used. When $R_{2}=2,5 \cdot 10^{-3} \mathrm{~m}$ we have $\gamma_{\max }=4000$.

Varied constants $A(z)$ and $B(z)$ are defined traditionally

$$
\begin{gathered}
A(z)=-\frac{\mu_{0} I_{0} N}{2 \gamma^{2}} W(\gamma, \Gamma) \int_{h+\delta}^{z} e^{-\gamma x} d x \\
B(z)=\frac{\mu_{0} I_{0} N}{2 \gamma^{2}} W(\gamma, \Gamma) \int_{h+\delta}^{z} e^{\gamma x} d x .
\end{gathered}
$$

where $R(\gamma, x) \equiv R(\gamma, z)$. Symbol $B$ in (7) marks the constant to be defined. Obviously, when $z \leq h+\delta$ the varied constants $A(z)=B(z)=0$.

As $\vec{H}^{(1)}(\rho, z)=\operatorname{rot}[\vec{A}(\rho, z)] / \mu_{0}$, then the amplitudes of the components of the intensity vector of alternating magnetic field in the half-space $z \geq h$ are determined as follows:

$$
\begin{gathered}
H_{\rho}^{(1)}(\rho, z)=-\frac{1}{\mu_{0}} A_{\varphi, z}(\rho, z) \\
H_{z}^{(1)}(\rho, z)=\frac{1}{\mu_{0}}\left(\frac{1}{\rho} A_{\varphi}(\rho, z)+A_{\varphi, \rho}(\rho, z)\right) .
\end{gathered}
$$

Let us determine the integral images of the components of the intensity vector of alternating magnetic field according to Hankel with the following expressions

$$
\begin{aligned}
& H_{\rho}^{(1)}(\gamma, z)=\int_{0}^{\infty} \rho H_{\rho}^{(1)}(\rho, z) J_{1}(\gamma \rho) d \rho, \\
& H_{z}^{(1)}(\gamma, z)=\int_{0}^{\infty} \rho H_{z}^{(1)}(\rho, z) J_{0}(\gamma \rho) d \rho .
\end{aligned}
$$

Influencing on (9) by the integral transformations (10) and (11), we obtain

$$
\begin{aligned}
& H_{\rho}^{(1)}(\gamma, z)=-\frac{\gamma}{\mu_{0}}\left\{\left[A_{0}+A(z)\right] e^{\gamma z}-[B+B(z)] e^{-\gamma z}\right\} \\
& H_{z}^{(1)}(\gamma, z)=\frac{\gamma}{\mu_{0}}\left\{\left[A_{0}+A(z)\right] e^{\gamma z}+[B+B(z)] e^{-\gamma z}\right\} .
\end{aligned}
$$

It follows from the computational formulas (12) and (13) and from the definitions of the variable constants $A(z)$ and $B(z)$ that at $z<h+\delta$ the expressions for calculating integral images $H_{\rho}(\gamma, z)$ and $H_{z}(\gamma, z)$ take the following form

$$
\begin{aligned}
& H_{\rho}^{(1)}(\gamma, z)=-\frac{\gamma}{\mu_{0}}\left(A_{0} e^{\gamma z}-B e^{-\gamma z}\right), \\
& H_{z}^{(1)}(\gamma, z)=\frac{\gamma}{\mu_{0}}\left(A_{0} e^{\gamma z}+B e^{-\gamma z}\right) .
\end{aligned}
$$

Let us determine the expressions for calculating the amplitude values $H_{\beta}^{*}(\rho, z)$ of the components of the intensity vector of alternating magnetic field in the volume of a magnetized ferromagnet.

The Maxwell equations in the volume of a conducting ferromagnet are written in the following form

$$
\begin{gathered}
\operatorname{rot} \vec{H}^{*}(\rho, z)=\vec{J}^{*}(\rho, z), \\
\operatorname{rot} \vec{E}^{*}(\rho, z)=-i \omega \vec{B}^{*}(\rho, z),
\end{gathered}
$$

where $\vec{J}^{*}(\rho, z)=\vec{e}_{\varphi} J_{\varphi}^{*}(\rho, z)$ is an amplitude value of the vector density of the eddy current conductivity;

$$
\begin{gathered}
-H_{\rho, z z}^{*}(\rho, z)+H_{z, \rho z}^{*}(\rho, z)+i \omega r_{0} \mu_{1}^{*} H_{\rho}^{*}(\rho, z)=0, \\
\frac{1}{\rho}\left[H_{\rho, z}^{*}(\rho, z)-H_{z, \rho}^{*}(\rho, z)\right]+H_{\rho, \rho z}^{*}(\rho, z)-H_{z, \rho \rho}^{*}(\rho, z)+i \omega r_{0} \mu_{3}^{\varepsilon} H_{z}^{*}(\rho, z)=0 .
\end{gathered}
$$

Let us define the integral images $H_{\rho}^{*}(\rho, z)$ and $H_{z}^{*}(\rho, z)$ by the identical expressions (10) and (11) of the relations, that is,
$\vec{E}^{*}(\rho, z)$ is an amplitude of the intensity vector of the eddy electric field; $\vec{B}^{*}(\rho, z)=\vec{e}_{\lambda} \mu_{\lambda \beta}^{\varepsilon} H_{\beta}^{*}(\rho, z)$ $(\beta, \lambda=\rho, z ; \rho \Leftrightarrow 1 ; z \Leftrightarrow 3)$ is an amplitude value of the vector of magnetic induction; $\vec{e}_{\lambda}$ is a unit vector of the cylindrical coordinate system.

Since $J_{\varphi}^{*}(\rho, z)=r_{0} E_{\varphi}^{*}(\rho, z)$, where $r_{0}$ is a specific electric conductivity, then the system of equations (15) becomes a vector equation of the following form

$$
\operatorname{rot}\left[\operatorname{rot}_{\varphi} \vec{H}^{*}(\rho, z)\right]+\vec{e}_{\lambda}\left[i \omega r_{2} \mu_{\lambda \beta}^{\varepsilon} H_{\beta}^{*}(\rho, z)\right]=0,
$$

where $\operatorname{rot}_{\varphi} \vec{H}^{*}(\rho, z)$ is a circumferential component of the rotor of the intensity vector of an alternating magnetic field in the volume of a ferromagnet.

Assuming that the matrix of the magnetic permeability tensor of a magnetized ferromagnet has a diagonal form, that is $\mu_{j k}^{\varepsilon}=\delta_{j k} \mu_{k}^{\varepsilon}$, and taking into account the equivalence relations between the symbols of the axes of Cartesian and cylindrical coordinate systems ( $\rho \Leftrightarrow 1 ; \varphi \Leftrightarrow 2 ; z \Leftrightarrow 3)$, we obtain from the vector equation (16) two scalar equations of the following form$$
H_{\rho}^{*}(\gamma, z)=\int_{0}^{\infty} \rho H_{\rho}^{*}(\rho, z) J_{1}(\gamma \rho) d \rho,
$$ 


$$
H_{z}^{*}(\gamma, z)=\int_{0}^{\infty} \rho H_{z}^{*}(\rho, z) J_{0}(\gamma \rho) d \rho
$$

Applying the integral transformation (19) to the equation (17), and the equation (18) to the transformation (20) we obtain a system of ordinary differential equations of the following form

$$
\begin{gathered}
-H_{\rho, z z}^{*}(\gamma, z)-\gamma H_{z, z}^{*}(\gamma, z)+i \omega r_{0} \mu_{1}^{*} H_{\rho}^{*}(\gamma, z)=0, \\
\gamma H_{\rho, z}^{*}(\gamma, z)+\gamma^{2} H_{z}^{*}(\gamma, z)+i \omega r_{0} \mu_{3}^{\varepsilon} H_{z}^{*}(\gamma, z)=0 .
\end{gathered}
$$

From the equation (22) it follows that

$$
H_{z}^{*}(\gamma, z)=-\frac{\gamma}{\gamma^{2}+i \omega r_{0} \mu_{3}^{\varepsilon}} H_{\rho, z}^{*}(\gamma, z)
$$

Substituting expression (23) into equation (21), we obtain

$$
H_{\rho, z z}^{*}(\gamma, z)-\zeta^{2} H_{\rho}^{*}(\gamma, z)=0,
$$

where $\zeta^{2}=\mu_{1}^{\varepsilon}\left(\gamma^{2}+i \omega r_{0} \mu_{3}^{\varepsilon}\right) / \mu_{3}^{\varepsilon}$ is a square of the complex wave number.

The solution for the equation (24) would be

$$
H_{\rho}^{*}(\gamma, z)=C e^{\zeta z}+D e^{-\zeta z},
$$

where $C$ and $D$ are the constants to be determined.

Substituting expression (25) into the definition (23), we obtain a formula for calculating the integral image of the axial component of the intensity vector of alternating magnetic field in the volume of a ferromagnetic plate

$$
\frac{1}{\rho}\left[H_{\rho, z}^{(2)}(\rho, z)-H_{z, \rho}^{(2)}(\rho, z)\right]+H_{\rho, \rho z}^{(2)}(\rho, z)-H_{z, \rho \rho}^{(2)}(\rho, z)-k_{0}^{2} H_{z}^{(2)}(\rho, z)=0 .
$$

As before, let us define the integral images of the vector components $\vec{H}^{(2)}(\rho, z)$ by the following Hankel transforms

$$
\begin{aligned}
& H_{\rho}^{(2)}(\gamma, z)=\int_{0}^{\infty} \rho H_{\rho}^{(2)}(\rho, z) J_{1}(\gamma \rho) d \rho, \\
& H_{z}^{(2)}(\gamma, z)=\int_{0}^{\infty} \rho H_{z}^{(2)}(\rho, z) J_{0}(\gamma \rho) d \rho .
\end{aligned}
$$

Applying the integral transformation (30) to the equation (28), and the transformation (31) to the equation (29), we obtain the following system of ordinary differential equations

$$
\begin{gathered}
-H_{\rho, z z}^{(2)}(\gamma, z)-\gamma H_{z, z}^{(2)}(\gamma, z)-k_{0}^{2} H_{\rho}^{(2)}(\gamma, z)=0 \\
\left(\gamma^{2}-k_{0}^{2}\right) H_{z}^{(2)}(\gamma, z)+\gamma H_{\rho, z}^{(2)}(\gamma, z)=0
\end{gathered}
$$

From the equation (33) it follows that

$$
H_{z}^{(2)}(\gamma, z)=-\frac{\gamma}{\gamma^{2}-k_{0}^{2}} H_{\rho, z}^{(2)}(\gamma, z)
$$

Substituting expression (34) into the equation (32), we obtain an equation for determining the integral image $H_{\rho}^{(2)}(\gamma, z)$ :

$$
H_{z}^{*}(\gamma, z)=-\frac{\mu_{1}^{\varepsilon} \gamma}{\mu_{3}^{\varepsilon} \zeta}\left(C e^{\zeta z}-D e^{-\zeta z}\right)
$$

The alternating magnetic field in region No.2, where $-\infty<z \leq-h$, satisfies Maxwell's equations in vacuum, from which the vector equation follows

$$
\operatorname{rot} \operatorname{rot} \vec{H}^{(2)}(\rho, z)-k_{0}^{2} \vec{H}^{(2)}(\rho, z)=0,
$$

where $\vec{H}^{(2)}(\rho, z)$ is an amplitude value of time-varying according to law $e^{i \omega t}$ intensity vector of the magnetic field; $\quad k_{0}^{2}=\omega^{2} \mu_{0} \chi_{0} ; \quad \mu_{0}=4 \pi \cdot 10^{-7} \mathrm{H} / \mathrm{m} \quad$ и $\chi_{0}=8,85 \cdot 10^{-12} \mathrm{~F} / \mathrm{m}$ are magnetic and dielectric constants. From the vector equation (27) there follow two scalar equations

$$
-H_{\rho, z z}^{(2)}(\rho, z)+H_{z, \rho z}^{(2)}(\rho, z)-k_{0}^{2} H_{\rho}^{(2)}(\rho, z)=0,
$$

$$
H_{\rho, z z}^{(2)}(\gamma, z)-\left(\gamma^{2}-k_{0}^{2}\right) H_{\rho}^{(2)}(\gamma, z)=0,
$$

The main contribution to the numerical values of the inverse Hankel transform is made by fragments of the integrand at the values $\gamma \in(500,1500)$. The latter allows us to state that at frequencies of hundreds of kilohertz - units of megahertz a strong inequality is always realized $\gamma^{2}>>k_{0}^{2}$. Then the solution for the equation (35) in the area $-\infty<z \leq-h$ is as follows:

$$
H_{\rho}^{(2)}(\gamma, z)=M e^{\gamma z}
$$

where $M$ is a constant. Applying (36) to the definition (34) considering that $\gamma^{2}>k_{0}^{2}$ we receive

$$
H_{z}^{(2)}(\gamma, z)=-M e^{\gamma}
$$

The constants $B, C, D$ and $M$ from boundary conditions on surfaces $z= \pm h$

$$
\begin{gathered}
H_{\rho}^{(1)}(\gamma, h)-H_{\rho}^{*}(\gamma, h)=0, \\
\mu_{0} H_{z}^{(1)}(\gamma, h)-\mu_{3}^{\varepsilon} H_{z}^{*}(\gamma, h)=0, \\
H_{\rho}^{*}(\gamma,-h)-H_{\rho}^{(2)}(\gamma,-h)=0,
\end{gathered}
$$




$$
\mu_{3}^{\varepsilon} H_{z}^{*}(\gamma,-h)-\mu_{0} H_{z}^{(2)}(\gamma,-h)=0 .
$$

The system of equations (38) is solved for constants to be defined in the only way.

$$
\begin{gathered}
C=-2 \gamma A_{0} e^{\gamma h} \frac{\beta_{1} e^{\zeta h}}{\mu_{0}\left(\beta_{1}^{2} e^{2 \zeta h}-\beta_{2}^{2} e^{-2 \zeta h}\right),} \\
D=2 \gamma A_{0} e^{\gamma h} \frac{\beta_{2} e^{-\zeta h}}{\mu_{0}\left(\beta_{1}^{2} e^{2 \zeta h}-\beta_{2}^{2} e^{-2 \zeta h}\right),},
\end{gathered}
$$

where $\beta_{1}=1+\mu_{1}^{\varepsilon} \gamma /\left(\mu_{0} \zeta\right) ; \beta_{2}=1-\mu_{1}^{\varepsilon} \gamma /\left(\mu_{0} \zeta\right)$.

Let us consider the case in which $h>R_{2}$. In this case, the ferromagnetic layer can be considered as a half-space (Fig. 2). Between the axial coordinates $z^{\prime}$ (Fig. 2) and $z$ (Fig. 1) there is an obvious relationship: $z=z^{\prime}+h$. When $h \rightarrow \infty$ :

$$
\begin{gathered}
H_{\rho}^{*}\left(\gamma, z^{\prime}\right)=\frac{I_{0} N}{\gamma} W(\gamma, \Gamma) \frac{\zeta e^{\zeta z^{\prime}}}{\left(\zeta+\mu_{1}^{\varepsilon} \gamma / \mu_{0}\right)}, \\
H_{z}^{*}\left(\gamma, z^{\prime}\right)=-\frac{I_{0} N}{\gamma} W(\gamma, \Gamma) \frac{\mu_{1}^{\varepsilon} \gamma e^{\zeta z^{\prime}}}{\mu_{3}^{\varepsilon}\left(\zeta+\mu_{1}^{\varepsilon} \gamma / \mu_{0}\right)} .
\end{gathered}
$$

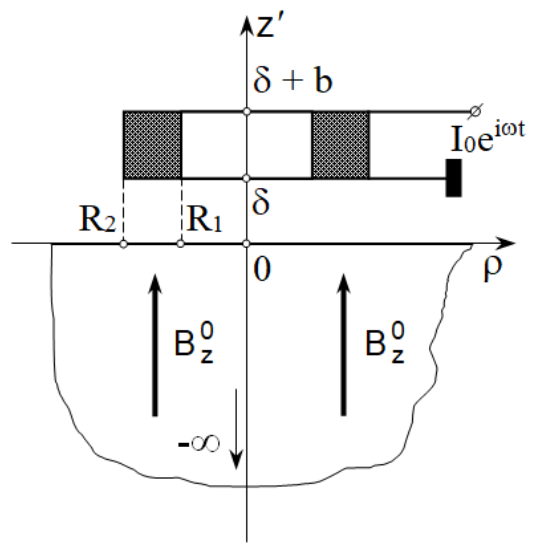

Fig. 2 - The model representation in the case of $h>>R_{2}$

Unknown functions $H_{\rho}^{*}\left(\rho, z^{\prime}\right)$ and $H_{z}^{*}\left(\rho, z^{\prime}\right)$ are determined by the inverse Hankel transformations, that is,

$$
\begin{aligned}
H_{\rho}^{*}\left(\rho, z^{\prime}\right) & =\int_{0}^{\infty} \gamma H_{\rho}^{*}\left(\gamma, z^{\prime}\right) J_{1}(\gamma \rho) d \gamma \\
H_{z}^{*}\left(\rho, z^{\prime}\right) & =\int_{0}^{\infty} \gamma H_{z}^{*}\left(\gamma, z^{\prime}\right) J_{0}(\gamma \rho) d \gamma .
\end{aligned}
$$

Substituting the expressions (40) into the transformations (41), we obtain the following calculation formulas for physical components of the complex-valued components of the intensity vector of alternating magnetic field:

$$
\begin{gathered}
\operatorname{Re} H_{\rho}^{*}\left(\rho, z^{\prime}\right) \cong \frac{I_{0} N}{R_{2}} \int_{0}^{x_{\max }} \operatorname{Re}\left(\frac{\zeta^{*} e^{\zeta^{*} z^{*}}}{\zeta^{*}+\mu_{1}^{\varepsilon} x / \mu_{0}}\right) W\left(x, \Gamma^{*}\right) J_{1}\left(x \rho^{*}\right) d x, \\
\operatorname{Re}_{z}^{*}\left(\rho, z^{\prime}\right) \cong-\frac{I_{0} N \mu_{1}^{\varepsilon}}{R_{2} \mu_{3}^{\varepsilon}} \int_{0}^{x_{\max }} \operatorname{Re}\left(\frac{x e^{\zeta^{*} z^{*}}}{\zeta^{*}+\mu_{1}^{\varepsilon} x / \mu_{0}}\right) W\left(x, \Gamma^{*}\right) J_{0}\left(x \rho^{*}\right) d x,
\end{gathered}
$$

where $x=\gamma R_{2}$ is a dimensionless integral transformation parameter; $\zeta^{*}=\sqrt{\mu_{1}^{\varepsilon}\left(x^{2}+i \omega r_{0} \mu_{3}^{\varepsilon} R_{2}^{2}\right) / \mu_{3}^{\varepsilon}}$ is a dimensionless complex wave number; $z^{*}=z^{\prime} / R_{2}$ is a dimensionless axial coordinate; is a set of dimensionless geometric parameters of the source of alternating magnetic field, that is, the set of values $R_{2}^{*}=1$, $R_{1}^{*}=R_{1} / R_{2}, \quad \delta^{*}=\delta / R_{2}, \quad b^{*}=b / R_{2} ; \quad \rho^{*}=\rho / R_{2} \quad$ is a dimensionless radial coordinate. The symbol $x_{\max }=\gamma_{\max } R_{2}$ defines the value, which is determined from $W(\gamma, \Gamma)$.

By the formulas (42) calculations were made with the value of $x_{\max }=20$. In this case, the integral was replaced by the algebraic sum of the mean values of the integrands within each section. When performing the calculations, the following parameters were recorded:: $R_{2}=3,5 \cdot 10^{-3} \mathrm{~m} ; \quad R_{1}=0,5 R_{2} ; \quad b=0,5 R_{2} ; \quad \delta=0,1 R_{2} ;$ $I_{0}=60 \mathrm{~A} ; \quad N=10 ; \quad \mu_{1}^{\varepsilon}=\mu_{3}^{\varepsilon}=30 \mu_{0}$; $\mu_{0}=4 \pi \cdot 10^{-7} \mathrm{H} / \mathrm{m} ; r_{0}=15 \mathrm{mS} / \mathrm{m}$.

On the surface of a ferromagnet, with small nega- tive values of the axial coordinate $z^{\prime}$, the nature of the variation of the real values of the components $H_{\rho}^{*}\left(\rho, z^{\prime}\right)$ and $H_{z}^{*}\left(\rho, z^{\prime}\right)$ in the region $\rho / R_{2} \geq 0$ can also be explained by the Fig. 3. The dashed curve in Fig. 3 shows the power line of alternating magnetic field. At each moment of time and at any point in the space, the vector $\vec{H}^{*}\left(\rho, z^{\prime}\right)$ is oriented along the tangent to this line.

With further immersion into the depth of the ferromagnetic half-space, the real values of the components $H_{\rho}^{*}\left(\rho, z^{\prime}\right)$ and $H_{z}^{*}\left(\rho, z^{\prime}\right)$ rapidly decrease to zero, after which the sign of the real part of alternating magnetic field is inversed. As the cyclic frequency increases, the plane $z^{\prime}=z_{0}^{\prime}$ of zero values (the sign inversion plane) of the real value of the intensity vector components of alternating magnetic field begins approaching to the plane $z^{\prime}=0$. In addition, in the region $z_{0}^{\prime} \leq z^{\prime} \leq 0$ with frequency increase, there is an increase in the real values of the radial component $H_{\rho}^{*}\left(\rho, z^{\prime}\right)$ and a decrease in the actual values of the 
axial component $H_{z}^{*}\left(\rho, z^{\prime}\right)$. This can be interpreted as "flattening" or squeezing out the alternating magnetic field of the inductor from the volume of a currentconducting ferromagnet. Obviously, all these effects are due to eddy currents conductivity $J_{\varphi}^{*}\left(\rho, z^{\prime}\right)$, which generates alternating magnetic field $\vec{H}^{*}\left(\rho, z^{\prime}\right)$ in the volume of a layer of a current-conducting ferromagnet.

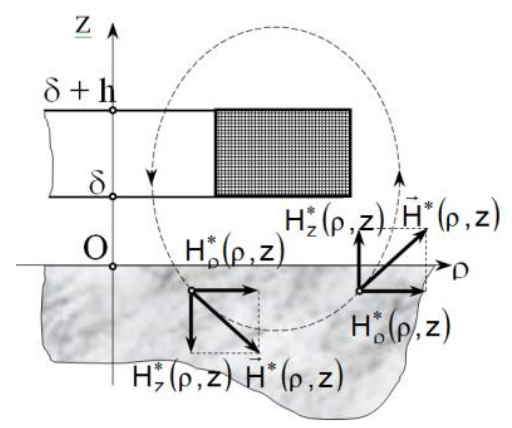

Fig. 3-To the explanation of the features of the change in the values of the intensity vector components of the magnetic field of the inductor

From the first equation of the system of Maxwell's equations (15) it follows that

$$
J_{\varphi}^{*}\left(\rho, z^{\prime}\right)=\operatorname{rot}_{\varphi} \vec{H}^{*}\left(\rho, z^{\prime}\right),
$$

where $\operatorname{rot}_{\varphi} \vec{H}^{*}\left(\rho, z^{\prime}\right)$ is a circumferential component of the vector $\operatorname{rot} \vec{H}^{*}\left(\rho, z^{\prime}\right)$. Substituting the expression (42) into the definition (43), after performing the differentiation operation under the integral sign, we obtain the following expression for calculating the real part of the complex value $J_{\varphi}^{*}\left(\rho, z^{\prime}\right)$ :

$$
\begin{aligned}
& \operatorname{Re} J_{\varphi}^{*}\left(\rho, z^{\prime}\right) \cong \\
& \cong \int_{0}^{x_{\max }} \operatorname{Re}\left[\frac{\left(\zeta^{* 2}-\mu_{1}^{\varepsilon} x^{2} / \mu_{3}^{\varepsilon}\right)}{\left(\zeta^{*}+\mu_{1}^{\varepsilon} x / \mu_{0}\right)} e^{\zeta^{*} z^{*}}\right] W\left(x, \Gamma^{*}\right) J_{1}\left(x \rho^{*}\right) d x
\end{aligned}
$$

The analysis of the calculations results using formula (44) allows to conclude that the plane coordinate $z_{0 J}^{\prime}$ of zero values of the real part of the complex density of the eddy current of conductivity does not coincide with the plane coordinate $z_{0}^{\prime}$ of the inversion of the sign of the real values of the components of the intensity vector of alternating magnetic field.

Ponderomotive effect of electromagnetic field over a metallic sample is defined by surface densities of Maxwell forces $\sigma_{z \rho}^{M}(\rho, t)=B_{z}^{0} H_{\rho}^{*}(\rho, 0) e^{i \omega t} \quad$ and $\sigma_{z z}^{M}(\rho, t)=0,5 B_{z}^{0} H_{z}^{*}(\rho, 0) e^{i \omega t}$, where $H_{\beta}^{*}(\rho, 0)$ $(\beta=\rho, z)$ are amplitude values of the components of the intensity vector of alternating magnetic field in the volume of the metal, determined on the surface $z^{\prime}=0$ of a metallic half-space.

The amplitude values of the components of the vector of the volume density of Lorentz forces are determined by the following expressions $f_{\rho}^{L}\left(\rho, z^{\prime}\right)=B_{z}^{0} J_{\varphi}^{*}\left(\rho, z^{\prime}\right), \quad f_{z}^{L}\left(\rho, z^{\prime}\right)=0, \quad$ where $J_{\varphi}^{*}\left(\rho, z^{\prime}\right)$ is an amplitude value of the surface density of the eddy current conductivity.

In a ferromagnetic metal, in addition to the deformations that are created by the ponderomotive action of the electromagnetic field, deformations appear due to the direct magnetostrictive effect or Joule effect. These deformations can be associated with Joule forces or magnetostrictive forces that are on the surface and in the volume of a ferromagnet. The surface density of Joule forces is determined by the following expressions:

$$
\begin{gathered}
\sigma_{z \rho}^{D}(\rho, t)=\frac{m_{1}-m_{2}}{2 \mu_{3}^{\varepsilon}} B_{z}^{0} H_{\rho}^{*}(\rho, 0) e^{i \omega t}, \\
\sigma_{z z}^{D}(\rho, t)=\frac{m_{1}}{\mu_{3}^{\varepsilon}} B_{z}^{0} H_{z}^{*}(\rho, 0) e^{i \omega t}
\end{gathered}
$$

If $B_{z}^{0} / \mu_{3}^{\varepsilon} \cong H_{z}^{0}$, where $H_{z}^{0}$ approximately corresponds to the magnetic field at the middle of the region of irreversible displacements of the domain walls on the initial magnetization curve [2], then the following estimate of the magnetostrictive constants is made: $m_{1} \leq 0,1 \mathrm{H} / \mathrm{m}, m_{2} \approx-m_{1} / 2$.

In the volume of a ferromagnet, the Joule forces are characterized by a volume density vector $\vec{f}^{D}\left(\rho, z^{\prime}\right) e^{i \omega t}$, for which the amplitude values of components are determined by the following expressions:

$$
\begin{gathered}
f_{\rho}^{D}(\rho, z)=\frac{\partial \sigma_{\rho \rho}^{D}(\rho, z)}{\partial \rho}+\frac{\partial \sigma_{\rho z}^{D}(\rho, z)}{\partial z}+\frac{1}{\rho}\left[\sigma_{\rho \rho}^{D}(\rho, z)-\sigma_{\varphi \varphi}^{D}(\rho, z)\right], \\
f_{z}^{D}(\rho, z)=\frac{\partial \sigma_{z \rho}^{D}(\rho, z)}{\partial \rho}+\frac{1}{\rho} \sigma_{z \rho}^{D}(\rho, z)+\frac{\partial \sigma_{z z}^{D}(\rho, z)}{\partial z} .
\end{gathered}
$$

Amplitude values of the surface densities $\sigma_{z \rho}^{D}(\rho, z)$ and $\sigma_{z z}^{D}(\rho, z)$ are given by the relations (45), in which instead of the values $H_{\beta}^{*}(\rho, 0)(\beta=\rho, z)$ it is necessary to use the components $H_{\beta}^{*}\left(\rho, z^{\prime}\right)$. The surface densities of the Joule forces $\sigma_{\rho \rho}^{D}\left(\rho, z^{\prime}\right)$ and $\sigma_{\varphi \varphi}^{D}\left(\rho, z^{\prime}\right)$ are defined as follows: $\quad \sigma_{\rho \rho}^{D}\left(\rho, z^{\prime}\right)=\sigma_{\varphi \varphi}^{D}\left(\rho, z^{\prime}\right)$ $=\left(m_{2} / \mu_{3}^{\varepsilon}\right) B_{z}^{0} H_{z}^{*}\left(\rho, z^{\prime}\right)$.

After determining the Hankel integral images of the amplitude values of the intensity vector components of alternating magnetic field and the eddy current conductivity in the volume of a ferromagnet, we can write the relations for calculating the integral images of the 
force factors that are in the skin layer and in the volume of magnetized, anisotropic based on magnetic properties metal, and which are sources of ultrasonic waves

a) ponderomotive forces of the electromagnetic field

$$
\begin{aligned}
& \sigma_{z \rho}^{M}(\gamma, 0)=\frac{I_{0} N B_{z}^{0}}{\gamma} \cdot \frac{\zeta W(\gamma, \Gamma)}{\left(\zeta+\mu_{1}^{\varepsilon} \gamma / \mu_{0}\right)} ; \\
& \sigma_{z \rho}^{D}(\gamma)=\frac{\left(m_{1}-m_{2}\right)}{2 \mu_{3}^{\varepsilon}} \frac{I_{0} N B_{z}^{0}}{\gamma} \frac{\zeta W(\gamma, \Gamma)}{\left(\zeta+\mu_{1}^{\varepsilon} \gamma / \mu_{0}\right)} ; \\
& \sigma_{z z}^{D}(\gamma)=-\frac{m_{1}}{\mu_{3}^{\varepsilon}} \frac{I_{0} N B_{z}^{0}}{\gamma} \frac{\mu_{1}^{\varepsilon} \gamma / \mu_{3}^{\varepsilon}}{\left(\zeta+\mu_{1}^{\varepsilon} \gamma / \mu_{0}\right)} W(\gamma, \Gamma) ; \\
& f_{\rho}^{D}\left(\gamma, z^{\prime}\right) \approx \frac{\left(m_{1}-m_{2}\right)}{2 \mu_{3}^{\varepsilon}} B_{z}^{0} \frac{\zeta}{\gamma} I_{0} N W_{K}(\gamma, \Gamma) e^{\zeta z^{\prime}} ; \\
& f_{z}^{D}\left(\gamma, z^{\prime}\right) \approx\left[\frac{\left(m_{1}-m_{2}\right)}{2 \mu_{3}^{\varepsilon}}-\frac{m_{1} \mu_{1}^{\varepsilon}}{\left(\mu_{3}^{\varepsilon}\right)^{2}}\right] B_{z}^{0} I_{0} N W_{K}(\gamma, \Gamma) e^{\zeta z^{\prime}} .
\end{aligned}
$$

Expressions (51) and (52) are written under the assumption that $|\zeta|>>\gamma$. Indeed, with moderate specific electrical conductivity $r_{0} \cong 10 \mathrm{mS} / \mathrm{m}$ and magnetic permeability $\quad \mu_{1}^{\varepsilon} \cong \mu_{3}^{\varepsilon}=30 \mu_{0}=3,77 \cdot 10^{-5} \mathrm{~m} \quad$ the product is $\omega r_{0} \mu_{3}^{\varepsilon}=2,37 \cdot 10^{9} f_{M H z}$, where $f_{M H z}$ is the value of the cyclic frequency in megahertz, in this case $\gamma^{2} \leq \gamma_{\max }^{2}=1,6 \cdot 10^{7}$.

The ratio $\gamma^{2} /\left(\omega r_{0} \mu_{3}^{\varepsilon}\right) \leq 6,75 \cdot 10^{-3} / f_{M H z}$ decreases with increasing frequency and becomes significantly less than unity, starting at a frequency of 100 kilohertz. For this reason $\xi^{2}=\gamma^{2}+i \omega r_{0} \mu_{3}^{\varepsilon} \cong i \omega r_{0} \mu_{3}^{\varepsilon}$ and $\zeta^{2}=i \omega r_{0} \mu_{1}^{\varepsilon}$, provided that $|\zeta| \gg>\gamma$. that

It follows from the calculated formulas (48) - (52)

$$
\frac{\sigma_{z \rho}^{M}(\gamma)}{\sigma_{z \rho}^{D}(\gamma)}=\frac{2 \mu_{3}^{\varepsilon}}{m_{1}-m_{2}}, \frac{\sigma_{z z}^{M}(\gamma)}{\sigma_{z z}^{D}(\gamma)}=\frac{\mu_{3}^{\varepsilon}}{m_{1}} .
$$

If the magnetostrictive constants $m_{1}$ and $m_{2}$ are not less than $0,1 \mathrm{H} / \mathrm{m}$, then $\mu_{3}^{\varepsilon}=30 \mu_{0}=3,77 \cdot 10^{-5} \mathrm{H} / \mathrm{m}$, the ratio of the surface densities of the ponderomotive forces of the electromagnetic field and the Joule forces, determined by expressions (53), take the following values $\sigma_{z \rho}^{M}(\gamma) / \sigma_{z \rho}^{D}(\gamma)=5,03 \cdot 10^{-4} \quad$ and $\sigma_{z z}^{M}(\gamma) / \sigma_{z z}^{D}(\gamma)=3,77 \cdot 10^{-4}$. Since the ratio of bulk densities is $f_{\rho}^{L}(\gamma) / f_{\rho}^{D}(\gamma)=2 \mu_{3}^{\varepsilon} /\left(m_{1}-m_{2}\right)=5,03 \cdot 10^{-4}$ , it can be concluded that with a correctly selected magnetization field of the ferromagnet, the Joule forces, namely the direct magnetostrictive effect, is the dominant mechanism for the formation of deformations in the electromagnetic method of excitation of ultrasonic waves in ferromagnetic metals. Naturally, there are no magnetostrictive effects in the non-ferromagnetic metals and the only mechanism for excitation of ultrasonic waves is the ponderomotive force of the electromagnetic field

Obviously, the surface densities of Joule forces $\sigma_{z \rho}^{D}(\rho)$ and $\sigma_{z z}^{D}(\rho)$ in the given model situation depend on the radial variable $\rho$ in the same way as the components $H_{\rho}^{*}(\rho, 0)$ and $H_{z}^{*}(\rho, 0)$. In other words, they change on the surface $z^{\prime}=0$ in the same way as the dependences under the numbers 1 in Fig. 4 and Fig. 5 . From this obvious fact it follows that at frequencies when the sign of alternating magnetic field is reversed $f \geq 100 \mathrm{kHz}$ and $\rho>0$ a strong inequality is satisfied $\left|\sigma_{z \rho}^{D}(\rho)\right|>>\left|\sigma_{z z}^{D}(\rho)\right|$.

The real parts of the volume density vector components of Joule forces are determined by the following expressions

$$
\begin{gathered}
\operatorname{Re} f_{\rho}^{D}\left(\rho, z^{\prime}\right) \cong \frac{I_{0} N B_{z}^{0}}{2 \mu_{3}^{\varepsilon} R_{2}^{2}}\left(m_{1}-m_{2}\right) \int_{0}^{x_{\max }} \operatorname{Re}\left(\frac{i \omega r_{0} \mu_{1}^{\varepsilon} R_{2}^{2}}{\zeta^{*}+\mu_{1}^{\varepsilon} x / \mu_{0}} e^{\zeta^{*} z^{*}}\right) W\left(x, \Gamma^{*}\right) J_{1}\left(x \rho^{*}\right) d x, \\
\operatorname{Re} f_{z}^{D}\left(\rho, z^{\prime}\right) \cong \frac{I_{0} N B_{z}^{0}}{2 \mu_{3}^{\varepsilon} R_{2}^{2}}\left[m_{1}\left(1-2 \mu_{1}^{\varepsilon} / \mu_{3}^{\varepsilon}\right)-m_{2}\right]_{0}^{x_{\max }} \operatorname{Re}\left(\frac{\zeta^{*} x}{\zeta^{*}+\mu_{1}^{\varepsilon} x / \mu_{0}} e^{\zeta^{*} z^{*}}\right) W\left(x, \Gamma^{*}\right) J_{0}\left(x \rho^{*}\right) d x .
\end{gathered}
$$

The formula (54) allowed to calculate and investigate the changes in radial and axial volumetric Joule force density vector components for the case of altering magnetic field, which changes with frequencies of $100 \mathrm{kHz}$ and $1 \mathrm{MHz}$. The value of the magnetic induc- 
tion of the bias field is $B_{z}^{0}=1 \mathrm{~T}$. Magnetostrictive constants are $m_{1}=0,1 \mathrm{H} / m, m_{2}=-m_{1} / 2$. As in the calculations of the magnetic field distributions and the eddy current of conductivity, a pronounced skin effect is clearly observed. The eddy currents in the volume of the ferromagnet push the magnetic field of the inductor to the surface of the current-conducting half-space. The layer thickness, in which noticeable values of the components of the bulk density of Joule's forces are observed, decreases sharply with increasing frequency. Since the axial component of the intensity vector of the alternating magnetic field decreases faster than the radial component, the radial component of the Joule force volume density vector in an axially magnetized ferromagnet increases somewhat, and the values of the axial component practically do not change with increasing frequency. It is quite clearly seen that the levels of the axial component of the bulk density vector are almost 30 times smaller than the values of the radial component. Thus, the following inequality $\left|f_{\rho}^{D}\left(\rho, z^{\prime}\right)\right| \gg\left|f_{z}^{D}\left(\rho, z^{\prime}\right)\right|$ is satisfied at frequencies $f \geq 100 \mathrm{kHz}$ and with $\rho>0$. Within the framework of the studied model it can be stated that the elastic deformations of a ferromagnet are mainly created by the radial components of the surface and bulk Joule forces, that is, components $\sigma_{z \rho}^{D}(\rho)$ and $f_{\rho}^{D}\left(\rho, z^{\prime}\right)$.

From the analysis of the presented model studies it also follows that the force impact that appears when the electromagnetic field is transformed in the field of ultrasonic vibrations in the skin layer of ferromagnetic metals, are formed in a small region with a radial dimension that does not exceed $(3 \div 4) R_{2}$. The latter makes it possible to apply integral transformations along a radial coordinate, for example, when solving problems of electromagnetic excitation of harmonic Rayleigh waves.

\section{CONCLUSIONS}

1. The physical principles of the creation of noncontact ultrasonic frequency sensors are developed, which convert a high-frequency controlled electromagnetic field into the field of elastic oscillations in the volume of a dynamically deformed micro-thick layer of an electrically conductive ferromagnet, taking into account the coupling of elastic and magnetic fields that allow the non-contact control and determination of the physical properties of nanostructured and film materials with the help of ultrasonic waves. Expressions for the force factors calculation that appear during the electromagnetic excitation of ultrasonic waves in the current-conducting axially magnetized skin layer of a ferromagnet are determined explicitly.

2. It is shown that the main contribution to the physical transformation is made by the ponderomotive forces of the electromagnetic field and the Joule forces, which correspond to elastic deformations appearing as a result of the demonstration of a direct magnetostrictive effect in the micro-thick layer of a ferromagnetic metal. With an optimal choice of the magnitude of the constant bias field, the Joule forces are almost four orders of magnitude greater than the ponderomotive forces produced by the electromagnetic field. It was established that the surface and bulk Joule forces participate in the same degree in the formation of dynamic deformations of an axially magnetized ferromag-net.

3. The inverse proportional relationship between the frequency of the electromagnetic field and the thickness of the skin layer of the ferromagnetic material in which the transformation takes place, allows maintaining layer-bylayer control and determining the physical and elastic properties of the material by changing the frequency of the current feeding the sensor.

4. It is established that the radially oriented Joule forces in an axially magnetized thin surface layer of a ferro-magnet at frequencies of the order of one megahertz are almost thirty times greater than axially oriented forces and that means that they dominate during the formation of ultrasonic high-frequency oscillations.

\title{
Физические основы создания бесконтактных ультразвуковых частотных сенсоров для исследования нанокристаллических ферромагнитных материалов
}

\author{
С.Ю. Плеснецов ${ }^{1}$ Р.П. Мигущенко ${ }^{1}$ О.Н. Петрищев², Г.М. Сучков ${ }^{1}$, А.Л. Хрипунова ${ }^{1}$
}

${ }^{1}$ Национальный технический университет "Харьковский политехнический институт», ул. Кирпичева, 2, 61002 Харьков, Украина

${ }^{2}$ Национальньй технический университет Украины "Киевский политехнический институт им. И. Сикорского", пр. Победь, 37, озо56 Киев, Украина

\begin{abstract}
Разработана математическая модель по определению силовых воздействий, формируемых при преобразовании электромагнитного поля в поле ультразвуковых колебаний в скин-слое электропроводного ферромагнитного материала анизотропного по магнитной проницаемости. Установлены основные фракторы, определяющие возбуждаемое акустическое поле с учетом допустимых ограничений. Показано, что основной вклад в энергетику акустических колебаний вносит магнитострикционная составляющая материала скин-слоя, в котором происходит преобразование высокочастотного электромагнитного поля в акустическое.
\end{abstract}

Ключевые слова: Математическая модель, Преобразование полей, Граничная задача, Скин-слой металла, Ферромагнетик, Электропроводный материал, Упругие колебания, Электромагнитное поле, Силовое воздействие. 


\title{
Фізичні основи створення безконтактних ультразвукових частотних сенсорів для дослідження нанокристалічних феромагнітних матеріалів
}

\section{С.Ю. Плеснецов ${ }^{1}$ Р.П. Мигущенкоํㅡㄹ О.М. Петрищев², Г.М. Сучков ${ }^{1}$, А.Л. Хрипунова ${ }^{1}$}

${ }^{1}$ Національний технічний університет “Харківський політехнічний інститут», вул. Кирпичова, 2, 61002 Харків, Україна

${ }^{2}$ Національний технічний університет Украӥни "Київський політехнічний інститут ім. I. Сікорського", пр. Перемоги, 37, 03056 Київ, Україна

\begin{abstract}
Розроблено математичну модель по визначенню силових впливів, які формуються при перетворенні електромагнітного поля в поле ультразвукових коливань в скін-шарі електропровідного феромагнітного матеріалу анізотропного по магнітній проникності. Встановлено основні фактори, що визначають збуджене акустичне поле з урахуванням допустимих обмежень. Показано, що основний внесок в енергетику акустичних коливань вносить магнітострикційна складова матеріалу скін-шару, в якому відбувається перетворення високочастотного електромагнітного поля в акустичне.
\end{abstract}

Ключові слова: Математична модель, Перетворення полів, Гранична задача, Скін-шар металу, Феромагнетик, Електропровідний матеріал, Пружні коливання, Електромагнітне поле, Силовий вплив.

\section{REFERENCES}

1. S.Yu. Plesnetsov, R.P. Migushchenko, O.N. Petryschev, G.M. Suchkov, G.S. Khrypunov, J. Nano- Electron. Phys. 9 No 5, 05041 (2017).

2. В.А. Боков, Физика магнетиков. Учебн. пос. для вузов (ФТИ им. А.Ф. Иоффе РАН. - СПб.:Невский Диалект;
БХВ-Петербург: 2002) (V.A. Bokov, Fizika magnetikov. Uchebn. pos. dlya vuzov (FTI im. A.F. Ioffe RAN. SPb.:Nevskiy Dialekt; BKHV-Peterburg: 2002)) [In Russian]. 